Journal of Environmental
Analysis and Progress
ISSN: $2525-815 \mathrm{X}$

\title{
Aptidão climática para o cultivo da banana em Caruaru-PE, Brasil
}

\section{Climate approach for banana cultivation in Caruaru-PE, Brazil}

\author{
Manoel Vieira de França ${ }^{a}$, Raimundo Mainar de Medeiros ${ }^{\mathrm{a}}$, Romildo Morant de Holanda ${ }^{\mathrm{a}}$, Vicente \\ de Paulo Silva ${ }^{\mathrm{a}}$, Juan Xavier Vieira Ferraz, Daniel de Morais Sobral ${ }^{\mathrm{a}}$
}

a Universidade Federal Rural de Pernambuco-UFRPE, Departamento de Tecnologia Rural-DTR, Rua Manuel de Medeiros, s/n, Dois Irmãos, Recife-PE. CEP: 52171-900. E-mail: manoelvieiraufrpe@gmail.com, mainarmedeiros@gmail.com, romildomorant@gmail.com, vicenteufrpe@yahoo.com.br, juan_ferraz@outlook.com, dmsobral@hotmail.com.

\begin{tabular}{|c|c|}
\hline A R T I C L E I N F O & A B S T RA C T \\
\hline $\begin{array}{l}\text { Recebido } 08 \text { Mar } 2018 \\
\text { Aceito } 18 \text { Jun } 2018 \\
\text { Publicado 29 Jun } 2018\end{array}$ & $\begin{array}{l}\text { The banana tree is a typically tropical plant, demanding high temperatures, well- } \\
\text { distributed precipitation, and availability of soil moisture. The banana (Musa } \\
\text { sapientum) is one of the most explored tropical fruits in the world. Improper } \\
\text { irrigation management can hamper plant growth and development, reducing } \\
\text { productivity. The study aimed to determine the variability of the climatic elements, } \\
\text { based on the calculation of the water balance and apply the climatic classification, } \\
\text { according to the methods of Thornthwaite and Köppen, for the municipality of } \\
\text { Caruaru, verifying the occurrence of the aptitude of the cultivar banana. Air } \\
\text { temperature data (maximum, minimum, mean and amplitude); relative humidity; } \\
\text { intensity and predominant wind direction; evaporation and evapotranspiration; total } \\
\text { sunshine, cloud cover, and precipitation were obtained from the agrometeorological } \\
\text { study, Banana planting is restricted because it presents a } 556.5 \text { mm water deficit } \\
\text { whose value is close to annual precipitation and evaporation ( } 573.8 \text { mm). Another } \\
\text { factor that aggravates banana cultivation in the area is the high evaporative power } \\
\text { that is registered in the municipal area, besides the lack of water for irrigation } \\
\text { supplementation. }\end{array}$ \\
\hline
\end{tabular}

Keywords: Implantation, factors and climatic elements.

\section{R E S U M O}

A bananeira é uma planta tipicamente tropical, exigente em temperaturas elevadas, precipitação bem distribuída e disponibilidade de umidade no solo. A banana (Musa sapientum) é uma das frutas tropicais mais exploradas mundialmente. Um manejo de irrigação inadequado pode prejudicar o crescimento e o desenvolvimento das plantas, diminuindo a produtividade. $\mathrm{O}$ estudo objetivou determinar a variabilidade dos elementos climáticos, a partir do cálculo do balanço hídrico e aplicar a classificação climática, segundo os métodos de Thornthwaite e Köppen, para o município de Caruaru, verificando a ocorrência da aptidão da cultivar banana. Os dados de temperatura do ar (máxima, mínima, média e amplitude); umidade relativa do ar; intensidade e direção predominante do vento; evaporação e evapotranspiração; insolação total, cobertura de nuvens e precipitação foram adquiridas do estudo agrometeorológico, correspondente ao período de anos de 1962-2016. O plantio de banana torna-se restrito por apresentar deficiência hídrica de $556,5 \mathrm{~mm}$ cujo valor aproxima-se da precipitação anual e evaporação $(573,8 \mathrm{~mm})$. Outro fator agravante para restrição do cultivo da banana na área é o alto poder evaporativo que se registra na área municipal além da falta de água para complementação pela irrigação. Palavras-Chave: Implantação, fatores e elementos climáticos.

\section{Introdução}

A bananeira (Musa sapientum) é uma planta típica da região tropical, necessitam de temperaturas

elevadas, precipitação uniformemente distribuída e disponibilidade de umidade no solo. A temperatura ótima para o 
desenvolvimento das bananeiras oscila em torno de $28^{\circ} \mathrm{C}$, enquanto temperaturas de $15^{\circ} \mathrm{C}$ e $35^{\circ} \mathrm{C}$ são os limites extremos para sua exploração como cultura. Se a região tem valores de temperatura dentro dos limites referenciados e possui suprimento de água e nutrientes, o cultivo da bananeira na área estudada é viável.

A banana é uma das frutas tropicais mais exploradas mundialmente. Devido ao seu custo relativamente baixo e ao alto valor nutritivo é parte integrante na alimentação, principalmente, das populações de baixa renda. O Brasil está entre os maiores produtores de banana do mundo, ocupando a terceira posição, com uma produção aproximada de 6,3 milhões de toneladas ao ano, em 2002, ocupando uma área de 508 mil hectares (FAO, 2006). Vale ressaltar que este fruto é cultivado em todos os Estados brasileiros, desde a faixa litorânea até os planaltos do interior. Entretanto, certos fatores climáticos, como a temperatura e o regime de chuvas, impõem limites à cultura, em conformidade com Borges et al. (2006).

$\mathrm{Na}$ cultura da bananeira, um manejo de irrigação inadequado pode prejudicar $\mathrm{o}$ crescimento e o desenvolvimento das plantas, diminuindo a produtividade. Sob severa deficiência hídrica, a roseta foliar da bananeira se comprime, dificultando, ou até mesmo impedindo, o lançamento da inflorescência. Consequentemente, o cacho pode não apresentar valor comercial, como afirmado por Moreira (1997).

Em função de sua morfologia e da hidratação de seus tecidos, a bananeira apresenta um elevado consumo de água. As maiores produções estão associadas a uma precipitação total anual de $1.900 \mathrm{~mm}$, bem distribuída no decorrer do ano, conforme relatado por Alves (1997). Em grande parte das regiões, onde a bananeira é cultivada, a precipitação é insuficiente para atender às necessidades hídricas, tornando-se necessário o uso de irrigação suplementar, como ocorre no semiárido nordestino.

As necessidades hídricas da planta estão intimamente relacionadas aos índices evaporativos, visto que a cultura depende, essencialmente, das condições microclimáticas, como: precipitação, intensidade do vento, temperatura do ar e umidade relativa do ar, radiação solar. Considerando as características da planta, estão: cultivar, estágio vegetativo, índice de área foliar, extensão e profundidade das raízes e atividade metabólica da planta, sem minimizar a quantidade de água disponível no solo, de acordo com Ferreira (1988).

Das diversas fruteiras tropicais irrigadas, a bananeira é uma planta muito sensível ao estresse hídrico; possui elevado índice de área foliar, o que resulta em alta transpiração, o sistema radicular é muito superficial, razão pela qual a bananeira é uma espécie que apresenta considerável resposta fisiológica à escassez de água, segundo Vosselen et al. (2005), além do fato de que demandam água ao longo de todo o ano, por se tratar de cultivo perene, com produção constante.

Matos et al. (2014) afirmam que o uso do balanço hídrico para uma região é de suma importância, pois o mesmo considera as características do solo como: textura física, profundidade efetiva do sistema radicular e o movimento de água no solo durante todo o ano. Para tanto, o método de classificação climática de Thornthwaite (1948) é amplamente utilizado, sendo esse em função de dados das normais climatológicas de temperatura, precipitação e evapotranspiração potencial (ETp), mais eficiente para detectar pequenas variações espaciais climáticas, quando comparada à classificação de Köppen (Cunha \& Martins, 2009).

De acordo com Silva et al. (2011), o sucesso das culturas exploradas em uma dada região depende da regularidade e da quantidade da precipitação. As variabilidades espaciais e temporais da precipitação pluvial nas regiões áridas e semiáridas são fatores limitantes para o cultivo de sequeiro, técnica de sobrevivência realizada por pequenos agricultores familiares no semiárido do nordeste do Brasil, segundo Alves (2013).

Para definir a aptidão da região para o cultivo da bananeira, o produtor deve ter conhecimento das características climatológicas e suas variações sazonais, uma vez que esta cultura não tolera encharcamento do solo, fortes ventos e temperaturas médias do ar abaixo de $15^{\circ} \mathrm{C}$, de acordo com Ventura \& Gomes (2005).

$\mathrm{O}$ estudo objetiva estudar a influência das variabilidades dos elementos climáticos, a partir do cálculo do balanço hídrico desenvolvido por Thornthwaite \& Mather $(1948,1955)$ e a classificação climática, segundo o método de Köppen (1928) na aptidão da cultivar banana em área sob restrição hídrica no município de CaruaruPE.

\section{Material e Métodos}

O município de Caruaru está localizado na mesorregião Agreste e na Microrregião do Vale do Ipojuca do Estado de Pernambuco, limitando-se, ao norte, com Toritama, Vertentes, Frei Miguel e Taquaritinga do Norte, ao sul, com Altinho e Agrestina, à leste, com Bezerros e Riacho das Almas, e à oeste, com Brejo da Madre de Deus e São Caetano (Figura 1). A sede do município tem altitude de $554 \mathrm{~m}$ e está localizado nas coordenadas 
geográficas $08^{\circ} 17^{\prime} \mathrm{S}$ latitude e $35^{\circ} 58^{\prime} \mathrm{W}$ longitude, com altitude média de 545 m (CPRM, 2005).

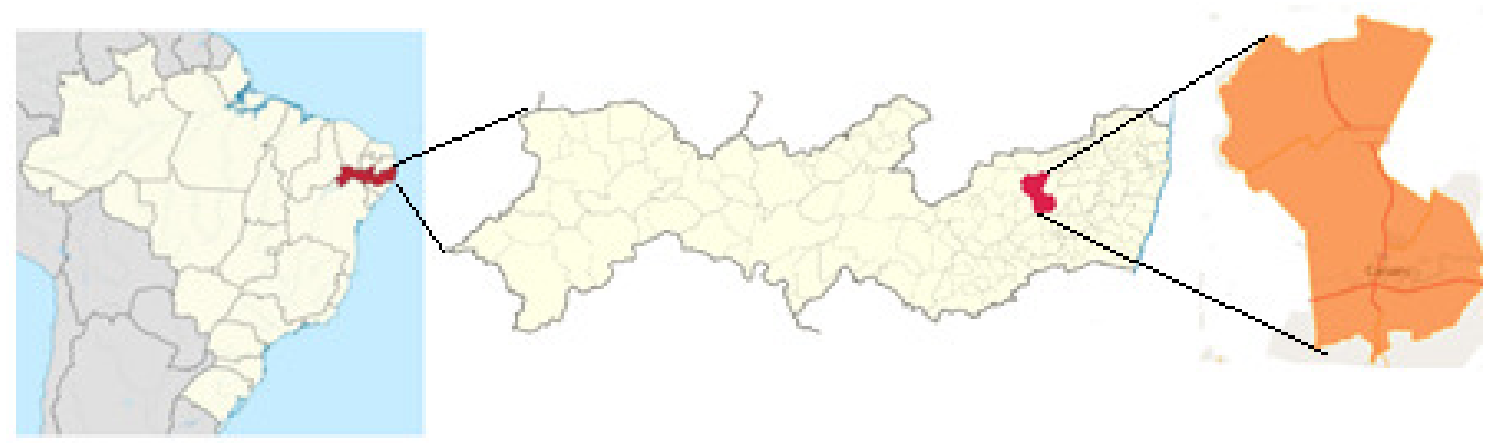

Figura 1. Localização do município de Caruaru, no Estado de PE. Fonte: Medeiros (2017).

O município de Caruaru está inserido na unidade geoambiental do Planalto da Borborema, formada por maciços e outeiros altos, com altitude variando entre 650 a 1.000 metros. Ocupa área de arco, que se estende do sul de Alagoas até o Rio Grande do Norte. O relevo é geralmente movimentado, com vales profundos e estreitos dissecados. A fertilidade dos solos é variada, com certa predominância de média para alta. Por se localizar nas terras da Borborema, o solo tem superfícies suaves onduladas, onde ocorrem os Planossolos, medianamente profundos, fortemente drenados, ácidos a moderadamente ácidos e fertilidade natural média e ainda os Podzólicos, que são profundos, textura argilosa, e fertilidade natural média a alta. Nas elevações ocorrem os solos Litólicos, rasos, textura argilosa e fertilidade natural média. Nos Vales dos rios e riachos, ocorrem os Planossolos, medianamente profundos, imperfeitamente drenados, textura média/argilosa, moderadamente ácidos, fertilidade natural alta e problemas de sais. Ocorrem afloramentos de rochas. O município é cortado por rios perenes de pequena vazão e o potencial de água subterrânea é baixo.

A vegetação é formada por Florestas Subcaducifólia e Caducifólia, características das áreas agrestes. Apresenta a caatinga como vegetação dominante do município, com espéciesarbóreas típicas, como: juazeiro, baraúna, mulungú, algaroba e imburana, arbustos do tipo velameiro, marmeleiro e urtiga, broméliaceas como ocaroá, macambira, gravatá e cactáceas do tipo facheiro, xique-xique, mandacarú, coroa-defrade e palmatória. Possui vegetação úmida e arborizada do tipo floresta tropical, ao sul, facilitada por ter divisa com o brejo pernambucano, no extremo sul do município.

O clima de Caruaru, de acordo com a classificação de Köppen-Geiger, é do tipo semiárido (BSh), com verões quentes e secos e invernos a menos e chuvosos, de acordo com Alvares et al. (2014). A quadra chuvosa se inicia em fevereiro, com chuvas de pré-estação (chuvas que ocorrem antes da quadra chuvosa) e término ocorrendo no final do mês de agosto, podendo se prolongar até a primeira quinzena de setembro. $\mathrm{O}$ trimestre chuvoso centra-se nos meses de maio, junho e julho e os meses mais secos ocorrem entre outubro e dezembro. Os fatores provocadores de chuvas no município são a contribuição da Zona de Convergência Intertropical (ZCIT), formação dos vórtices ciclônicos de altos níveis (VCAS), quando seu centro se posiciona sobre o oceano ocorre a influência da contribuição dos ventos alísios de nordeste no transporte de vapor e umidade que se condensa e forma nuvens, as formações das linhas de instabilidades, a orografia e suas contribuições locais, de acordo com Medeiros (2016).

A utilização do método de Thornthwaite \& Mather (1948, 1955) demanda informações de precipitação e temperatura média do ar para a realização do cálculo do balanço hídrico do município de Caruaru,. As Planilhas eletrônicas para o cálculo do balanço hídrico foram desenvolvidas por Medeiros (2016). Tomou-se o valor de capacidade de água disponível no solo (CAD) de $100 \mathrm{~mm}$; e como valor de referência para deficiência hídrica (DEF) adotou-se o valor de 100 $\mathrm{mm}$. Portanto, deficiência hídrica anual de $\mathrm{DEF}=$ $100 \mathrm{~mm}$, considerado o limite, acima do qual a faixa se torna restrita a inapta para a cultura da banana.

Os dados de precipitação e temperatura médias foram adquiridos do banco de dados da superintendência do desenvolvimento do Nordeste (SUDENE, 1990) e pela Agência pernambucana de água e clima (APAC, 2016), para o período de 1913 a 2016.

Os dados climatológicos médios mensais foram aplicados a planilhas eletrônicas, para obterem-se os valores de médias mensais e anuais de temperatura do ar e precipitação, imprescindíveis ao cálculo do balanço hídrico pelo método de Thornthwaite \& Mather $(1948,1955)$. A proeminência da estimativa do balanço hídrico para 
o município de Caruaru está pautada na importância que a água tem para o seu desempenho do armazenamento de água no solo, a sobrevivência humana, irrigação, agricultura e laser.

Nos cálculos do balanço hídrico climatológico (BHC) utilizaram-se do valor de CAD representativos dos solos encontrados da região de estudo $(\mathrm{CAD}=100 \mathrm{~mm})$ para solo com alta capacidade de armazenamento, como os solos aluvionais do município. Com base no BHC aplicaram-se as metodologias de Thornthwaite (1948) e Thornthwaite \& Mather (1955) para a classificação climática, de acordo com os valores de CAD predeterminados.

A maior parte do sistema radicular da bananeira concentra-se nos primeiros $40 \mathrm{~cm}$ de profundidade do solo. A prática da subsolagem deve ser realizada sempre que for feito o cultivo da bananeira pela primeira vez e por ocasião da reforma do plantio velho. A bananeira exige solos bem arejados, portanto, a drenagem é necessária para os solos que apresentem tendência ao alagamento ou encharcamento.

A cultura da banana tem faixas de temperatura que contribuem para seu desenvolvimento: Temperatura média anual $(\mathrm{Ta})=$ $15^{\circ} \mathrm{C}$ indica o limite inferior da faixa térmica apta à produção da banana. Abaixo desse limite, a cultura apresenta deficiência térmica, que provoca queda na produção, tornando-se a área restrita e inapta para a comercialização. a) Temperatura média anual (Ta) entre $15^{\circ} \mathrm{C}$ e $35^{\circ} \mathrm{C}$ indica a faixa térmica favorável à cultura da banana. (b) Temperatura média anual (Ta) maior que $35^{\circ} \mathrm{C}$ indica o limite superior da faixa térmica favorável à cultura da banana.

Os dados de temperatura do ar (máxima, mínima, média e amplitude); umidade relativa do ar; intensidade e direção predominante do vento; evaporação e evapotranspiração; insolação total, cobertura de nuvens e precipitação foram adquiridas do estudo agrometeorológico desenvolvido por Medeiros (2016), correspondendo ao período de 1962-2016.

A classificação climática seguiu o método proposto por Thornthwaite e por Köppen, descritos em Vianello \& Alves (1991). O tipo climático da região foi definido pelo método de Thornthwaite, com base nos valores dos índices hídrico (Ih), aridez (Ia), umidade (Iu) e de eficiência térmica (TE), os quais são em função da evapotranspiração potencial, da deficiência e do excedente hídrico, resultantes dos cálculos da contabilidade hídrica. A classificação proposta por Köppen leva em consideração os dados médios de temperatura do ar e precipitação da região, associados a uma simbologia que representa os tipos e variedades climáticas.

\section{Resultados}

As análises relacionadas às variabilidades dos elementos meteorológicos nos apontam flutuações ocorridas entre os anos de 1913-2016, para a precipitação pluvial do município de Caruaru, como contribuição ao estudo da cultura da banana e condições propícias ao cultivo.

Os valores médios climatológicos dos elementos meteorológicos estudados para o município de Caruaru, referentes ao período de 1962 a 2016, estão apresentados na Tabela 1.

Tabela 1. Normais climatológicas para o município de Caruaru (1962 a 2016). Fonte: Medeiros (2017).

\begin{tabular}{|c|c|c|c|c|c|c|c|c|c|c|c|c|c|}
\hline \multirow{2}{*}{ Parâmetros } & \multicolumn{13}{|c|}{$1962-2016$} \\
\hline & jan & fev & mar & abr & mai & jun & jul & ago & set & out & nov & dez & anual \\
\hline $\begin{array}{l}\text { Temperatura } \\
\text { máxima }\end{array}$ & 29,7 & 30,0 & 29,3 & 28,4 & 27,1 & 25,4 & 24,4 & 25,4 & 26,8 & 29,1 & 30,1 & 30,4 & 28,0 \\
\hline $\begin{array}{l}\text { Temperatura } \\
\text { mínima }\end{array}$ & 19,7 & 19,8 & 20,1 & 20,0 & 19,3 & 18,4 & 17,3 & 17,4 & 17,9 & 18,6 & 19,3 & 19,6 & 19,0 \\
\hline $\begin{array}{l}\text { Temperatura } \\
\text { média }\end{array}$ & 23,9 & 24,1 & 24,1 & 23,6 & 22,7 & 21,6 & 20,6 & 20,9 & 21,7 & 23,1 & 24,7 & 24,2 & 22,9 \\
\hline Amplitude térmica & 10,0 & 10,2 & 9,2 & 8,4 & 7,8 & 7,0 & 7,1 & 8,0 & 8,9 & 10,5 & 10,8 & 10,8 & 9,1 \\
\hline Insolação & 222,9 & 199,9 & 198,0 & 175,1 & 166,4 & 140,3 & 141,5 & 180,7 & 185,1 & 247,0 & 253,2 & 248,4 & 2358,5 \\
\hline Cobertura nuvem & 0,6 & 0,6 & 0,7 & 0,7 & 0,8 & 0,8 & 0,8 & 0,7 & 0,7 & 0,6 & 0,6 & 0,6 & 0,7 \\
\hline Evapotranspiração & 107,2 & 101,4 & 110,6 & 99,1 & 90,4 & 75,4 & 68,3 & 71,8 & 78,3 & 97,8 & 115,6 & 114,4 & 1130,3 \\
\hline Evaporação & 33,8 & 47,6 & 63,8 & 73,5 & 80,1 & 75,4 & 68,3 & 49,6 & 32,7 & 16,2 & 15,7 & 17,0 & 573,8 \\
\hline $\begin{array}{l}\text { Umidade relativa } \\
\text { ar }\end{array}$ & 75,1 & 75,2 & 78,6 & 81,3 & 83,1 & 85,7 & 85,8 & 83,8 & 79,9 & 74,9 & 50,0 & 72,4 & 77,2 \\
\hline Precipitação & 33,5 & 47,5 & 63,7 & 73,4 & 80,1 & 92,0 & 80,5 & 42,3 & 23,7 & 8,9 & 12,4 & 15,9 & 573,8 \\
\hline Intensidade vento & 1,9 & 1,8 & 1,8 & 1,8 & 1,9 & 1,8 & 2,1 & 2,1 & 2,1 & 2,1 & 2,3 & 2,1 & 2,0 \\
\hline $\begin{array}{l}\text { Direção } \\
\text { predominante }\end{array}$ & SE & SE & SE & SE & SE & SE & SE & SE & SE & SE & SE & SE & SE \\
\hline Fotoperíodo & $12: 47$ & $12: 35$ & $12: 17$ & $12: 23$ & $12: 11$ & $11: 56$ & $12: 04$ & $12: 24$ & $12: 07$ & $12: 30$ & $12: 35$ & $12: 44$ & $12: 19$ \\
\hline
\end{tabular}




\begin{tabular}{lccccccccccccc} 
Deficiência hídrica & 73,3 & 53,7 & 46,8 & 25,6 & 10,3 & 0,0 & 0,0 & 22,1 & 45,6 & 81,6 & 100,0 & 97,4 & 556,5 \\
Excedente hídrico & 0,0 & 0,0 & 0,0 & 0,0 & 0,0 & 0,0 & 0,0 & 0,0 & 0,0 & 0,0 & 0,0 & 0,0 & 0,0 \\
\hline
\end{tabular}

As temperaturas médias do município oscilaram entre $20,6^{\circ} \mathrm{C}$, em julho, a $24,7^{\circ} \mathrm{C}$, em novembro, com valor anual médio de $22,9^{\circ} \mathrm{C}$. A flutuação da temperatura mínima mensal oscila de $17,3^{\circ} \mathrm{C}$, no mês de julho, a $20,1^{\circ} \mathrm{C}$, no mês de março, com temperatura anual de $19^{\circ} \mathrm{C}$ (Figura 2), amplitude térmica anual de $9,1^{\circ} \mathrm{C}$ e variação mensal oscilando entre $7,8^{\circ} \mathrm{C}$, em maio, a $10,8^{\circ} \mathrm{C}$, nos meses de novembro e dezembro. A temperatura máxima oscila entre $24,4^{\circ} \mathrm{C}$, no mês de julho, a $30,4^{\circ} \mathrm{C}$, em dezembro, com uma temperatura máxima anual de $28^{\circ} \mathrm{C}$.

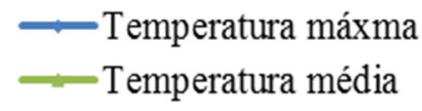

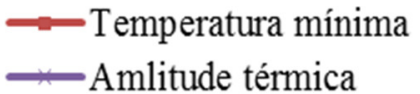

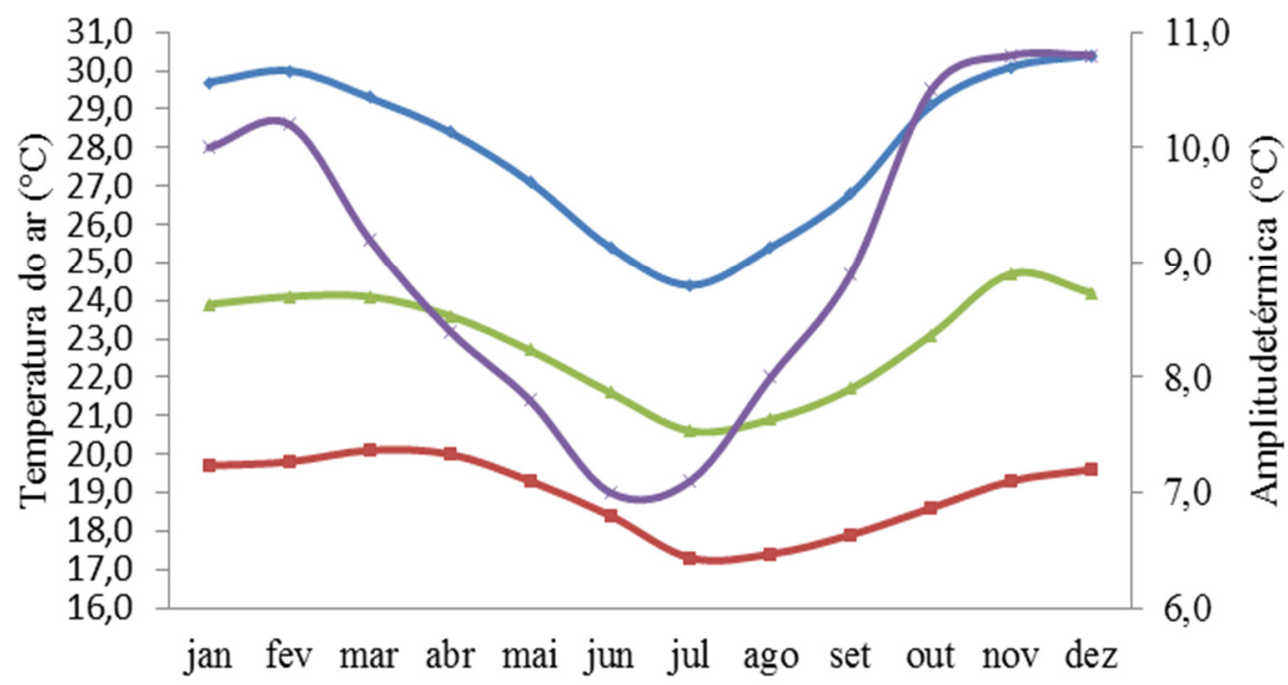

Figura 2. Variação média anual de temperatura máxima, média, mínima e amplitude térmica do município de Caruaru, no período de 1962-2016. Fonte: Medeiros (2017).

O vento é outro elemento climático importante, podendo causar, desde pequenos danos, até a destruição do bananal. A velocidade do vento foi inferior a $8,33 \mathrm{~m} \cdot \mathrm{s}^{-1}$, geralmente não prejudica a planta, ou seja, não é limitante para o cultivo da banana.

A variabilidade média mensal e anual da intensidade do vento na região é apresentada na Figura 3. Nos meses de janeiro e maio, a intensidade média foi de $1,9 \mathrm{~m} . \mathrm{s}^{-1}$. Nos meses de junho a outubro., registrou-se uma intensidade de 2,1 m. $\mathrm{s}^{-1}$, nos meses de fevereiro, março, abril e junho registrou-se $1,8 \mathrm{~m} \cdot \mathrm{s}^{-1} \mathrm{e}$, no mês de novembro, o valor foi de $2,3 \mathrm{~m} \cdot \mathrm{s}^{-1}$. A intensidade média anual foi de $2 \mathrm{~m} \cdot \mathrm{s}^{-1}$. No que se refere à velocidade do vento, mais importante do que a média diária ou mensal, é seu valor instantâneo ao longo do dia, pois uma rajada de vento, ou um vendaval que ocorre em alguns minutos, é capaz de provocar a destruição do bananal. Salienta-se que nestes valores não estão contabilizadas as rajadas de vento que ocorrem na área. A direção predominante do vento médio anual e mensal é na direção sudeste (SE).

A irregularidade mensal nos índices pluviométricos é decorrente dos fatores meteorológicos inibidores e/ou ativadores dos sistemas provocadores de chuva na área em estudo, com auxílio das contribuições local e regional.

Na Figura 4 observam-se as flutuações da precipitação climatológica e umidade relativa do ar, referente ao período de 1962-2016, para o município de Caruaru. A irregularidade mensal nos índices pluviométricos é decorrente dos fatores meteorológicos inibidores e/ou ativadores dos sistemas provocadores de chuva na área em estudo, com auxílio das contribuições local e regional. 


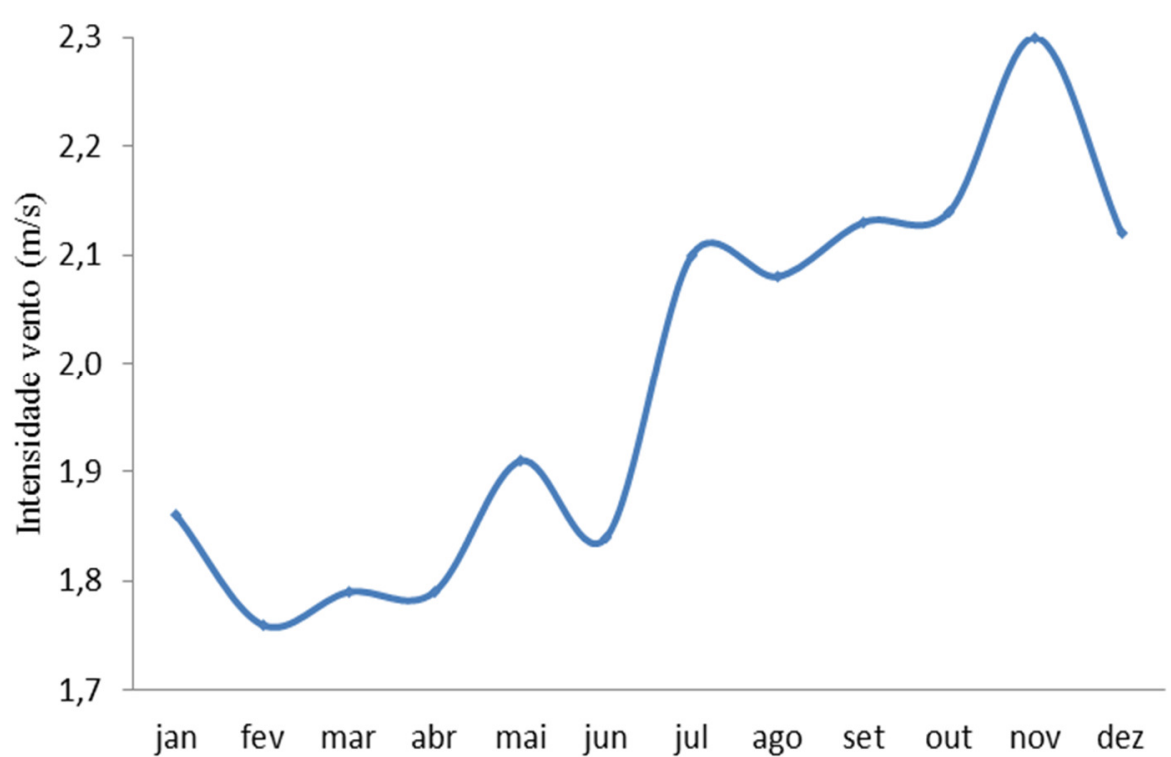

Figura 3. Variação média anual da intensidade do vento no município de Caruaru, no período de 1962-2016. Fonte: Medeiros (2017).

O município de Caruaru registra um índice pluviométrico de $573,4 \mathrm{~mm} \cdot \mathrm{ano}^{-1}$. Os meses de março a julho, onde ocorrem as maiores incidências de precipitação, contribuem com $68 \%$ do índice anual. Entre agosto e fevereiro, meses onde os índices pluviais são baixos, existe a contribuição de $32 \%$ do valor anual (Figura 4).

A umidade relativa do ar oscila entre 50\%, no mês de novembro, e $85,8 \%$, no mês de julho, com $77,2 \%$ de umidade anual. $\mathrm{O}$ trimestre de baixa umidade do ar compreende os meses de outubro a dezembro, com oscilações entre 50 e $74,5 \%$. Os meses de junho a agosto compreendem o trimestre de alta umidade e suas flutuações ocorrem entre 83,8 e $85,8 \%$. O mês de baixa umidade é novembro (50\%) e o de alta umidade é o de julho $(85,8 \%)$.

A umidade relativa média da área estudada é inferior às médias anuais e mensais, adequadas para a bananeira, que apresenta melhor desenvolvimento em locais com médias anuais de umidade relativa do ar superior a $80 \%$ (Figura 4). Esse limite é decorrente da origem da espécie, proveniente de regiões tropicais úmidas.

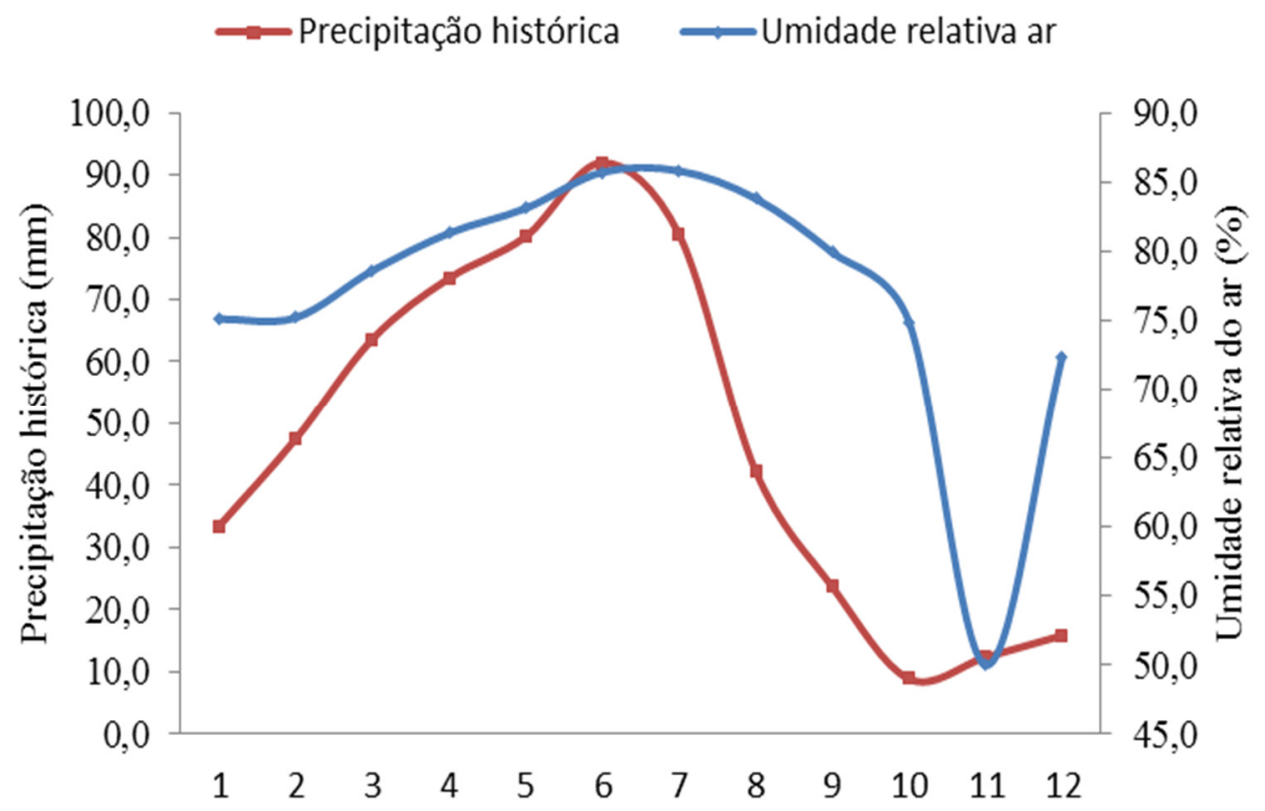

Figura 4. Flutuações da precipitação climatológica e umidade relativa do ar referente ao período de 1962-2016 para o município de Caruaru. Fonte: Medeiros (2018).

No município de Caruaru faz-se necessário o uso de irrigações durante os meses de agosto a maio, visto que neste período ocorre déficit hídrico; os valores registrados para a precipitação não 
cobrem tal demanda, salienta-se que a água de subsolo não garante o uso na irrigação.

É possível observar as flutuações da evaporação e evapotranspiração referentes ao período de 1962-2016 da área estudada (Figura 5). Destaca-se que a evapotranspiração é maior que a evaporação entre os meses de janeiro a maio e de agosto a dezembro e, nos meses de junho e julho, estes valores se igualam.

A evapotranspiração oscila entre $68,3 \mathrm{~mm}$, no mês de julho, e $115,6 \mathrm{~mm}$, em novembro. A evapotranspiração anual é de $1.130,3 \mathrm{~mm}$, quase uma vez e meia o valor da precipitação anual, o quadrimestre de maior poder evaporativo é de novembro a fevereiro e o quadrimestre de menor poder evapotranspirativo ocorre nos meses de junho a setembro. A evaporação flui entre 15,7 mm, no mês de novembro, a $80,1 \mathrm{~mm}$, no mês de maio, com taxa anual de $573,8 \mathrm{~mm}$, com precipitação de $5 \mathrm{~mm}$ a mais que o valor anual da evaporação.

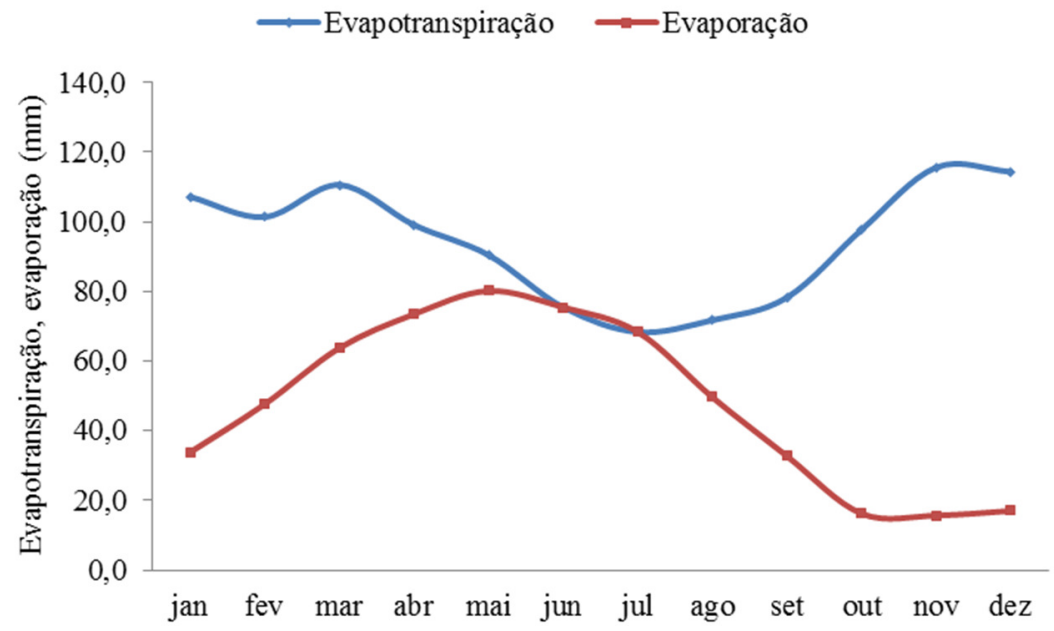

Figura 5. Variação média da evaporação, evapotranspiração do município de Caruaru, no período de 1962 2016. Fonte: Medeiros (2017).

As variabilidades da insolação total e cobertura nuvem são apresentadas (Figura 6). Destaca-se aumento na cobertura de nuvem entre os meses de março a setembro e reduções entre outubro a fevereiro, os meses de maio, junho, julho têm cobertura de 0,8 décimos e nos meses de outubro a janeiro, a cobertura de nuvem é de 0,6 décimos. A cobertura de nuvem anual é de 0,7 décimos.
$\mathrm{Na}$ curva da insolação total ocorre o inverso da cobertura de nuvem. A insolação anual é de 2.358,5 horas, o mês de maior insolação é novembro, enquanto junho é o de menor. O quadrimestre de maior incidência solar corresponde os meses de outubro a janeiro, e nos meses de abril a junho registram-se as menores incidências de insolação.

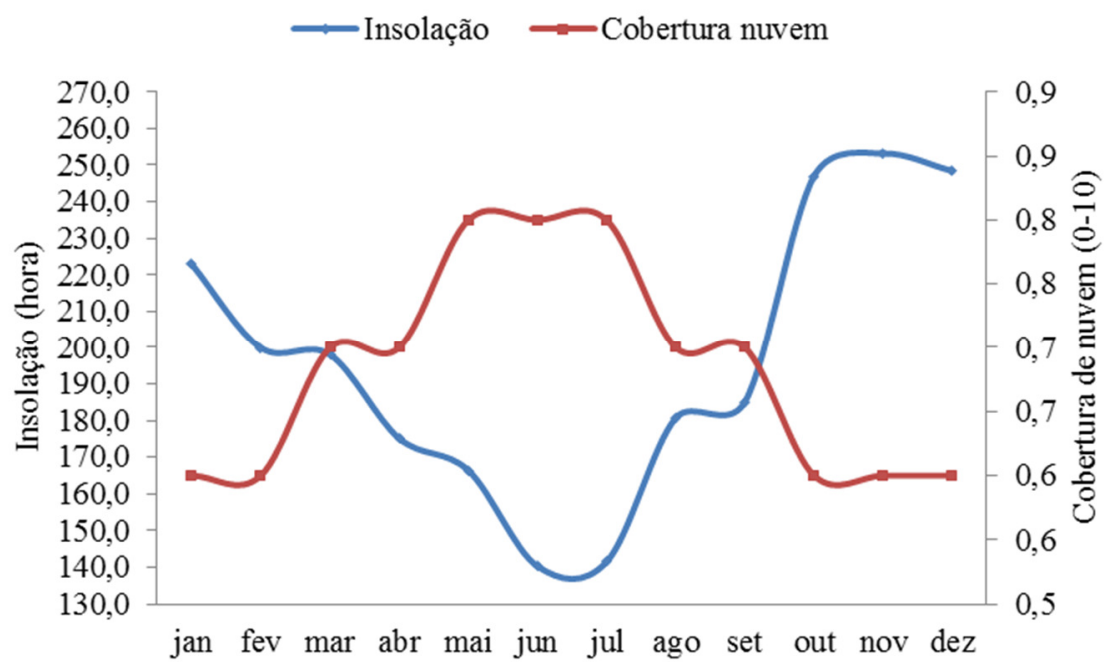

Figura 6. Variação média anual da insolação e nebulosidade no município de Caruaru, no período de $1962-$ 2016. Fonte: Medeiros (2017). 
Quando não é detectado excedente, isto significa que a precipitação é igual ou aproximada à evaporação real anual. É apresentado um quadro resumo da aptidão climática da cultura da bananeira (Tabela 2).

Tabela 2. Aptidão climática da cultura da bananeira em Caruaru. Fonte: EMBRAPA (210).

\begin{tabular}{lll}
\hline Aptidão & Índice climático & Deficiência/Excesso \\
\hline Plena & Def $<200 \mathrm{~m}$ & $\begin{array}{l}\text { Boas condições hídricas para o desenvolvimento da } \\
\text { cultura. }\end{array}$ \\
Moderada & $200<\operatorname{Def}<350 \mathrm{~m}$ & $\begin{array}{l}\text { Insuficiência hídrica estacional, prolongando o ciclo } \\
\text { da cultura. }\end{array}$ \\
Restrita & $350<$ Def $<700 \mathrm{~m}$ & $\begin{array}{l}\text { Deficiência hídrica acentuada, sendo possível o } \\
\text { cultivo apenas em várzeas e locais mais úmidos. } \\
\text { Deficiência hídrica muito severa. O cultivo somente } \\
\text { é possível através de irrigação. }\end{array}$ \\
\hline
\end{tabular}

$\mathrm{Na}$ área municipal não foram detectados excedentes. Em contraste com os moderados excessos de água do período chuvoso, o período seco, além de relativamente longo, possui normalmente grandes déficits de água, prolongando-se de agosto a maio, com exceção para os meses de junho e julho, os quais se apresentam com valor zero. A deficiência anual é de 556,5 mm (Tabela 3).

Tabela 3. Balanço hídrico climatológico do município de Caruaru, segundo Thornthwaite \& Mather (1955) $(\mathrm{CAD}=100 \mathrm{~mm})$. Fonte: Medeiros (2017).

\begin{tabular}{cccccc}
\hline Meses & Precipitação & Evapotranspiracão & Evaporação & Deficiência hídrica & Excedente hídrico \\
mm & \multicolumn{4}{c}{} \\
\hline Jan & 33,5 & 107,2 & 33,8 & 73,3 & 0,0 \\
Fev & 47,5 & 101,4 & 47,6 & 53,7 & 0,0 \\
Mar & 63,7 & 110,6 & 63,8 & 46,8 & 0,0 \\
Abr & 73,4 & 99,1 & 73,5 & 25,6 & 0,0 \\
Mai & 80,1 & 90,4 & 80,1 & 10,3 & 0,0 \\
Jun & 92,0 & 75,4 & 75,4 & 0,0 & 0,0 \\
Jul & 80,5 & 68,3 & 68,3 & 0,0 & 0,0 \\
Ago & 42,3 & 71,8 & 49,6 & 22,1 & 0,0 \\
Set & 23,7 & 78,3 & 32,7 & 45,6 & 0,0 \\
Out & 8,9 & 97,8 & 16,2 & 81,6 & 0,0 \\
Nov & 12,4 & 115,6 & 15,7 & 100,0 & 0,0 \\
Dez & 15,9 & 114,4 & 17,0 & 97,4 & \\
\hline
\end{tabular}

Os resultados mostram que não existe a ocorrência de excedente hídrico entre os meses do ano. As deficiências hídricas ocorrem entre os meses de agosto a maio, sendo os meses de outubro a janeiro os de elevadas taxas de deficiência, é recomendável complementar a lâmina de água no solo através do uso de irrigação, principalmente nos meses citados, quando ocorre perda de água do solo por evaporação. Ocorre reposição de água no solo nos meses de junho e julho e a retirada de água no solo ocorre entre os meses de agosto a dezembro; as deficiências hídricas predominam entre os meses de setembro a maio. Os Excedentes hídricos não ocorrem para a CAD de $100 \mathrm{~mm}$ (Figura 7). Os índices de umidade, aridez e hídricos são: $49,24 \% ; 0,49 \%$ e $-0,30 \%$, respectivamente. 


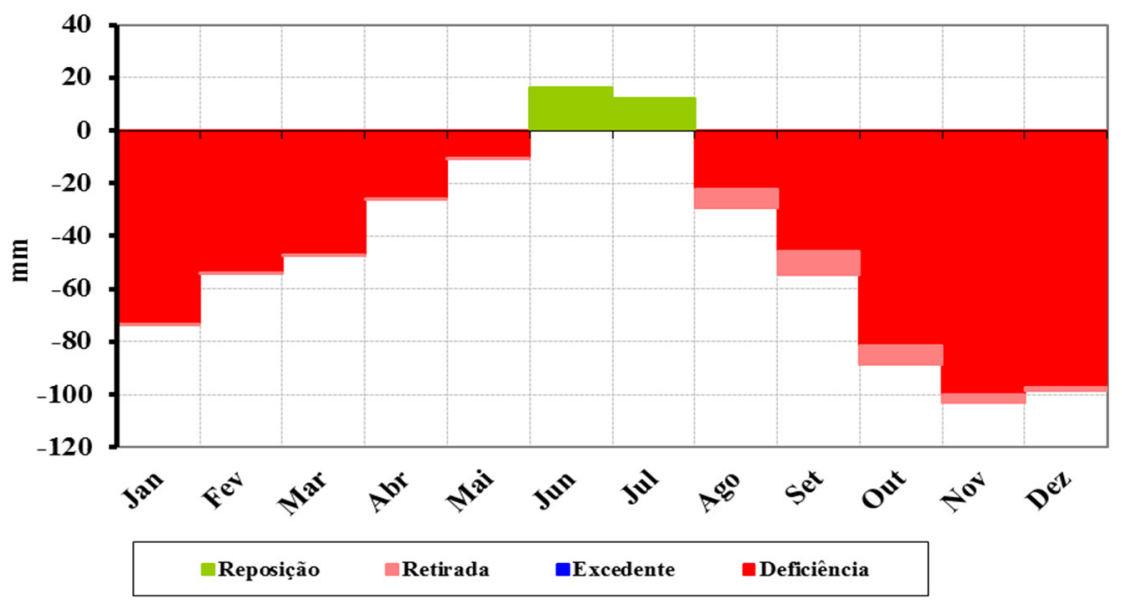

Figura 7. Gráfico do balanço hídrico climatológico do município de Caruaru segundo Thornthwaite \& Mather (1955). Período: 1962 - 2016. Fonte: Medeiros (2017).

\section{Discussão}

Considerando que o município de Caruaru apresenta altitude média de $545 \mathrm{~m}$, satisfatória para o cultivo da bananeira, que, segundo Alves (1997), deve ser cultivada em locais com altitude variando entre 0 e $1.000 \mathrm{~m}$ acima do nível do mar. As oscilações na altitude alteram a duração do ciclo da bananeira, evidenciando-se que há um aumento de 30 a 45 dias no ciclo de produção desta cultura, para cada $100 \mathrm{~m}$ de acréscimo na altitude (Alves, 1997).

O efeito da luminosidade sobre o ciclo vegetativo da bananeira é evidenciado, como plantio adensado. Em locais com elevada insolação, o período para que o cacho atinja ponto de corte oscila entre 80 e 90 dias. Após sua emissão, sob pouca insolação, o período para que o cacho atinja o ponto de corte comercial pode variar entre 85 e 112 dias.

Por outro lado, verifica-se um aumento da atividade fotossintética na faixa luminosa entre 2.000 e 10.000 lux, sendo mais lenta na faixa de 10.000 a 30.000 lux. Valores inferiores a 1.000 lux são insuficientes para o desenvolvimento da planta, e valores elevados podem acarretar a queima das folhas, principalmente quando estas estão na fase de cartucho (Alves, 1997).

\section{Conclusões}

O plantio de banana torna-se restrito por apresentar deficiência hídrica de 556,5 mm, cujo valor aproxima-se da precipitação anual e da evaporação $(573,8 \mathrm{~mm})$. Outro fator agravante para a restrição do cultivo da banana na área é o alto poder evaporativo que se registra na área municipal, além da falta de água para complementação através da irrigação.

\section{Referências}

ALVARES, C. A.; STAPE, J. L.; SENTELHAS, P. C.; GONÇALVES, J. L. M.; SPAROVEK, G. 2014. Köppen's climate classification map for Brazil. Meteorologische Zeitschrift, v. 22, p. 711728.

ALVES, T. L. B.; AZEVEDO, P. V. 2013. Caracterização agroclimática para a microbacia hidrográfica do Riacho Namorado, São João do Cariri-PB. XVIII Congresso Brasileiro de Agrometeorologia, Centro de eventos Benedito Nunes, Belém-PA.

ALVES, E. J. 1997. A cultura da banana: aspectos técnicos, socioeconômicos e agroindustriais. Brasília: EMBRAPA-SPI; Cruz das Almas: EMBRAPA CNPMF. 585p.

CUNHA, A. R.; MARTINS, D. 2009. Classificação climática para os municípios de Botucatu e São Manuel, SP. Revista Irriga, v. 14, n. 1, p. 1-11.

FAO. 2006. Statistical databases. Disponível em: http:// www.fao.org. Acesso em: 02 fev.

FERREIRA, E. J. 1988. Determinação da evapotranspiração e do coeficiente de cultura $(\mathrm{Kc})$ para a aveia preta (Avena strigosa, Sckereb) irrigada. 70f. Dissertação (Mestrado em Agronomia). Universidade Federal de Viçosa, Viçosa-MG.

KÖPPEN, W.; GEIGER, R. "Klimate der Erde. Gotha: Verlag Justus Perthes". Wall-map $150 \mathrm{~cm} \times 200 \mathrm{~cm} .1928$.

MATOS, R. M.; SILVA, J. A. S.; MEDEIROS, R. M. 2014. Aptidão climática para a cultura do feijão 
caupi do município de Barbalha-CE. Revista Brasileira de Agricultura Irrigada, v. 8, n. 6, p. 422431.

MEDEIROS, R. M. 2016. Estudo agrometeorológico para o Estado do Pernambuco. 128p., Divulgação Avulsa.

MEDEIROS, R. M. 2016. Planilhas eletrônicas para o cálculo do balanço hídrico.

MEDEIROS, R. M. 2017. Estudo agrometeorológico e balanço hídrico para o Estado do Pernambuco. 125p., Divulgação avulsa.

MOREIRA, R. S. 1997. Banana: teoria e prática de cultivo. Campinas: Fundação Cargill. 335p.

SILVA, V. P. R.; PEREIRA, E. R. R.; AZEVEDO, P. V.; SOUSA, F. A. S.; SOUSA, I. F. 2011. Análise da pluviometria e dias chuvosos na região
Nordeste do Brasil. Revista Brasileira de Engenharia Agrícola e Ambiental, v. 15, n. 2, p. 131-138.

THORNTHWAITE, C. W. 1948. An approach toward a rational classification of climate. Geogr. Rev., v. 38, p. 55-94.

THORNTHWAITE, C. W.; MATHER, J. R. 1955. The water balance. Publications in Climatology. New Jersey: Drexel Institute of Technology, 104p.

VENTURA, J. A.; GOMES, J. A. 2005.Recomendações técnicas para o cultivo de bananeira no Estado do Espírito Santo. Vitória ES. Incaper. 42p.

VIANELlO, R. L.; ALVES, A. R. 1991. Meteorologia básica e Aplicações. Viçosa-MG. Imprensa Universitária. 449p. 